\title{
A Comparative Study of the Peak Expiratory Flow Rate of Indian and Nepalese Young Adults in a Teaching Institute
}

\author{
'Debray P, 'Shreevatsa BM, ' MG RB, ' Sen TK, '2 Roy S, 'Saha CG \\ 'Department of Physiology, ${ }^{2}$ Department of Anatomy, Manipal College of Medical Sciences, Pokhara, Nepal.
}

\section{ABSTRACT}

Peak expiratory flow rate (PEFR) measurement is the easiest and cheapest method to evaluate respiratory functions. So, the study was carried out to evaluate PEFR of healthy Nepalese adults and compare their values with healthy Indian counterparts to know whether Indian prediction equations for PEFR can be used for Nepalese adult population or not.

One hundred twenty-three healthy, young, non smoker adult Indian (64: 28 Males, 36 Females) and Nepalese (59: 32 Males, 27 Females) medical students of 18 to 20 years of age participated in the study. The mean PEFR of Indian (male: 490.4 liter/min, female: 386.0 liter/min) and Nepalese (male: 485.9 liter/min, Female: 365.2 liter/min) young adults were found to have no significant differences.

As there is no significant difference in the mean PEFR of Indian and Nepalese young adults, prediction equations made for Indian adults can be used to predict PEFR of Nepalese subjects. Therefore, an attempt has been made to formulate a regression equation from the combined Indian and Nepalese subjects. A stepwise, multiple, linear, regression analysis was performed for this purpose. The analysis showed that height is the best predictor for PEFR in the present study. The regression equation based on height for the combined Indian and Nepalese young adults is calculated as: PEFR $=5.687 \times$ Height (cm) - 495.787. However, a stepwise, multiple, linear, regression equation with residual analysis for the best fit model was performed to formulate prediction equation for PEFR and this showed a change of the earlier regression equation to PEFR $=5.930 \times$ Height $(\mathrm{cm})-536.131$.

Keywords: Peak expiratory flow rate, peak flow meter, prediction equation, spirometry, young adults

\author{
Correspondence: \\ Dr. Parthasarathi Debray \\ Department of Physiology \\ Manipal College of Medical Sciences \\ Pokhara, Nepal. \\ Email: debray12@rediffmail.com
}

Running Title: PEFR of Indian and Nepalese young adults 
Debray et al. PEFR of Indian and Nepalese young adults

\section{INTRODUCTION}

Pulmonary function tests using complete spirometry give quantifiable measures of the state of the respiratory system and positive information for the management of respiratory tract illness in clinical practice. However, the required instruments are relatively expensive. In contrast, the Peak Expiratory Flow Rate (PEFR) can be measured using relatively inexpensive Peak Flow Meters and are of value in identifying and assessing the degree of air flow limitations of individuals. ${ }^{1}$ Many studies on PEFR in the general population have been carried out previously in India and abroad. ${ }^{2-12}$ Only one published study was found on PEFR of Nepalese females with a smoking habit in Nepal. ${ }^{13}$ No such study of normal Nepalese children and young adults was found. It is not possible to establish a national PEFR norm in a country for healthy men and women as the lung function varies with socio-economic, geographical, environmental and nutritional conditions. ${ }^{14,15} \mathrm{Nepal}$ is a neighboring country of India and its socio-economic, geographical, environmental and nutritional conditions of the relation are quite similar with respect to India. So, an attempt has been made to evaluate the value of PEFR of healthy Nepalese adults and compare their value with healthy Indian counterparts to know whether Indian prediction equations for PEFR can be used for the Nepalese adult population or not.

\section{MATERIAL AND METHODS}

The present study is a cross-sectional study carried out on 123 non-smoking, healthy medical students of 18 to 20 years of age studying at the Manipal College of Medical Sciences (MCOMS) in Pokhara, Nepal. Students of basic sciences ( $1^{\text {st }}$ to $4^{\text {th }}$ semester) during the year 2005 to 2006 participated in the present study. A detailed medical history of the students was taken and clinical examination of individuals carried out by physicians to exclude any disease, mainly respiratory diseases. A healthy person was defined as one who did not have any systemic disease. ${ }^{8}$ After medical tests, 123 healthy students were selected for the present study. Among the 123 students, 64 (28 Males, 36 Females) were Indians and 59 (32 Males, 27 Females) were Nepalese, by birth.

A verbal consent of all the 123 students was taken after they were explained the methods and a live of the study. A formal approval to conduct the study was taken from the MCOMS, Pokhara, Nepal. The necessary materials and instruments study were provided by the Department of Physiology of the MCOMS.

The age in completed year, standing height to the nearest centimeter without shoes and body weight in kilograms in minimum clothing were recorded for each subject at the Department of Physiology, MCOMS, Pokhara.

\section{Peak Expiratory Flow Rate (PEFR)}

PEFR was measured in the standing position with the 'standard range FERRARIS Pocket Peak Flow Meter' manufactured by FERRARIS Medical limited, London. ${ }^{16,17}$ The subjects were asked to relax before taking the PEFR measurement. The test procedure was explained to the subjects. After adequate rest, subjects were instructed to take a deep breath and exhale as forcefully as possible in once single blow into the instrument. During breathing out into the instrument the nose was closed by a nose clip. Three satisfactory readings were taken and the highest among the three was accepted. Close watch was made to ensure that a tight seal was maintained between the lips and the mouth piece. The PEFR was recorded nearest to Liter/ minutes. ${ }^{18,19}$

The collected data was stored in a computer for analysis and Statistical Package for the Social Sciences (SPSS) version 10 was used for this purpose. The mean and the SD for all the selected variables and comparisons between Nepalese and Indians were performed by student t-test. A stepwise, multiple, linear, regression equation with residual analysis for best the fit of the model was performed to formulate the prediction equation for PEFR from age and anthropometric data.

\section{RESULTS}

Comparisons of the physical characteristics including PEFR of the Indian and Nepalese young adults are shown in Table 1. Indian male young adults were found to have a PEFR of $490.4( \pm 49.85)$, whereas Nepalese male young adults were found to have 485.9 $( \pm 56.67)$. There is no statistical significant difference between these two populations. On the other hand, the mean PEFR values of the Indian female young adults were found to be $386.0( \pm 48.31) \mathrm{L} / \mathrm{min}$ as compared to $365.2( \pm 55.43)$ of the Nepalese counterparts. Here too, there also no significant difference between the two populations.

Comparisons of physical characteristics including PEFR of the male and female young adults of the Indian and Nepalese populations was done (Table 2). Both Indian and Nepalese male students are found to have a significantly higher PEFR value as compared to their female counterparts.

Stepwise, multiple, linear, regression analysis shows that height is the best predictor for PEFR (Figure 1 and Table 3). The regression equation based on height for the combined subjects is: PEFR $=5.687 \times$ Height $(\mathrm{cm})$ $-495.787$. 
Debray et al. PEFR of Indian and Nepalese young adults

Table 1. Comparisons of physical characteristics including PEFR of the Indian and Nepalese young adults

\begin{tabular}{|c|c|c|c|c|}
\hline \multirow{2}{*}{ Variables } & \multicolumn{2}{|c|}{ Male $(n=60)$} & \multicolumn{2}{|c|}{ Female $(n=63)$} \\
\hline & Indian $(n=28)$ & Nepali $(n=32)$ & Indian $(n=36)$ & Nepali $(n=27)$ \\
\hline Age (years) & $18.9( \pm 0.92)$ & $20.1( \pm 1.05)^{*}$ & $18.9( \pm 1.06)$ & $19.6( \pm 1.74) \dagger$ \\
\hline Height (cm) & $173.6( \pm 6.55)$ & $167.2( \pm 5.36)^{*}$ & $156.6( \pm 4.41)$ & $154.8( \pm 3.73) \dagger$ \\
\hline Weight (kg) & $68.4( \pm 9.57)$ & $58.4( \pm 5.88) *$ & $57.3( \pm 11.50)$ & $51.6( \pm 5.74) \ddagger$ \\
\hline BSA (m2) & $1.82( \pm 0.15)$ & $1.65( \pm 0.09)^{*}$ & $1.56( \pm 0.154)$ & $1.48( \pm 0.07)^{*}$ \\
\hline BMI (kg/m2) & $22.7( \pm 2.32)$ & $20.92( \pm 2.22)^{*}$ & $23.3( \pm 4.03)$ & $21.57( \pm 2.53) \ddagger$ \\
\hline PEFR (L/min) & $490.4( \pm 49.85)$ & $485.9( \pm 56.67) \dagger$ & $386.0( \pm 48.31)$ & $365.2( \pm 55.43) \dagger$ \\
\hline
\end{tabular}

Students' $t^{\prime}$ test was performed to see the significant difference; ${ }^{*} p<0.01,{ }^{\dagger}$ not significant ${ }^{\ddagger} p<0.05$ ，

Table 2. Comparisons of physical characteristic including PEFR of the male and female young adults of India and Nepal

\begin{tabular}{lllll}
\hline \multirow{2}{*}{ Variables } & \multicolumn{2}{c}{ Indian $(\mathbf{n}=64)$} & \multicolumn{2}{c}{ Nepalese $(\mathbf{n}=59)$} \\
& Male $(\mathbf{n}=\mathbf{2 8})$ & Female $(\mathbf{n}=\mathbf{3 6})$ & Male $(\mathbf{n = 3 2 )}$ & Female $(\mathbf{n}=\mathbf{2 7})$ \\
\hline Age (years) & $18.9( \pm 0.92)$ & $18.9( \pm 1.06)^{*}$ & $20.1( \pm 1.05)$ & $19.6( \pm 1.74)^{*}$ \\
Height $(\mathrm{cm})$ & $173.6( \pm 6.55)$ & $156.6( \pm 4.41) \dagger$ & $167.2( \pm 5.36)$ & $154.8( \pm 3.73) \dagger$ \\
Weight $(\mathrm{kg})$ & $68.4( \pm 9.57)$ & $57.3( \pm 11.50) \dagger$ & $58.4( \pm 5.88)$ & $51.6( \pm 5.74) \dagger$ \\
BSA $(\mathrm{m} 2)$ & $1.82( \pm 0.15)$ & $1.56( \pm 0.154) \dagger$ & $1.65( \pm 0.09)$ & $1.48( \pm 0.07) \dagger$ \\
BMI $(\mathrm{kg} / \mathrm{m} 2)$ & $22.7( \pm 2.32)$ & $23.3( \pm 4.03)^{*}$ & $20.92( \pm 2.22)$ & $21.57( \pm 2.53)^{*}$ \\
PEFR $(\mathrm{L} / \mathrm{min})$ & $490.4( \pm 49.85)$ & $386.0( \pm 48.31) \dagger$ & $485.9( \pm 56.67)$ & $365.2( \pm 55.43) \dagger$ \\
\hline
\end{tabular}

Students ' $\mathrm{t}$ ' test was performed to see the significant difference; ${ }^{*}$ not significant, $\dagger p<0.01$,

Table 3. Regression models for predicting PEFR in the Indian and Nepalese young adults (combined)

\begin{tabular}{|c|c|c|c|c|c|c|c|}
\hline \multirow{2}{*}{ Data Set } & \multirow{2}{*}{ Sample size } & \multicolumn{2}{|c|}{ Regression variables } & \multirow{2}{*}{ (R) } & \multirow{2}{*}{$\left(\mathbf{R}^{2}\right)$} & \multirow{2}{*}{ SEE } & \multirow{2}{*}{$\begin{array}{l}\text { Residua Standard } \\
\text { Deviation (RSD) }\end{array}$} \\
\hline & & Constant & Height & & & & \\
\hline Full & 123 & -495.787 & 5.687 & $0.671 *$ & 0.450 & 57.394 & 57.158 \\
\hline Reduced $^{\dagger}$ & 117 & -536.131 & 5.93 & $0.739 *$ & 0.546 & 48.500 & 48.310 \\
\hline
\end{tabular}

* $\mathrm{P}<0.001 ; \mathrm{R}$, Multiple Correlation coefficients; $\mathrm{R}^{2}$, Adjusted Multiple correlation coefficients; SEE, standard error of estimate; ${ }^{\dagger} \mathrm{Six}$ data have been omitted due to large standard residual (standard residual greater than or equal to 2);

The result of fitting model of regression equation shown in Table 3 (full data) established that height was statistically significant in predicting the PEFR. The overall fitting model statistics for the significance of regression model was found to be $P<0.001$. The residual plot of the predicted value of response variable vs. the standardized residual did not show any pattern and the residuals were randomly distributed around the mean value zero (0). However, there were six points which were large residuals (greater than or equal to 2 in absolute value). Therefore, we omitted these six outlines $^{20,21}$ and re-estimated the regression model as seen in the results of Table 3 (reduced data, $n, 117$ ) that the proportion of explained variation $\left(r^{2}\right)$ increased to $54 \%$ as compared to $45 \%$ (in full data; $n, 123$ ). On the other hand, the residual standard deviation (RSD) reduced to approximately $9 \%$ (RSD 57.158 to 48.310). So, as per residual analysis to fit best model, 
Debray et al. PEFR of Indian and Nepalese young adults

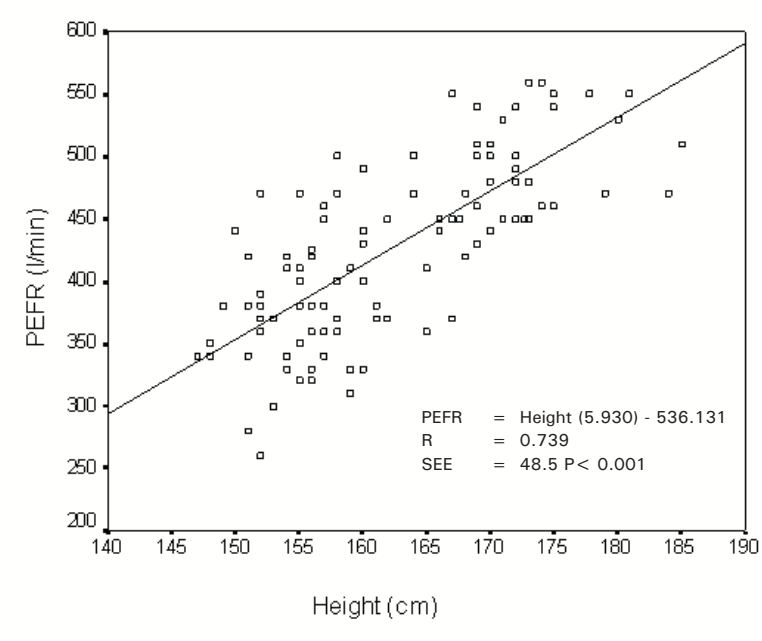

Figure 1. Linear regression analysis depicting the prediction of PEFR from height of the Indian and Nepalese young adults (reduced combined data. $\mathrm{N}=117$ )

the prediction equation is changed to: $\mathrm{PEFR}=5.930$ $\times$ Height $(\mathrm{cm})-536.131$.

\section{DISCUSSION}

Various workers have studied the PEFR values in healthy individuals. ${ }^{2-12}$ We studied the PEFR values of Nepalese healthy adults and compared them with the Indian counterparts. We found that there is no significant difference in the mean PEFR values of Indian and Nepalese healthy young adults (Table 2). The mean PEFR value of Indian male and female adults is well corroborated with the values found in an Indian study. ${ }^{8}$ However, the PEFR values of the present study are found to be smaller than another Indian study. ${ }^{5}$

There is no such work performed primarily to measure PEFR value of Nepalese healthy adults. There are many studies carried out in India to measure PEFR and their predictions equations. ${ }^{2,7}$ In our study, we found that there is no such significant difference in PEFR obtained between Indians and Nepalese healthy adults. So, it may be recommended that prediction equations made from Indian studies can be used to predict the PEFR of Nepalese healthy young adults. Therefore, we tried to formulate the prediction equation by different physical parameters with combined subjects (both males and females) by stepwise multiple linear regression analysis. We found that height is the best predictor to measure PEFR. This finding is highly correlated with other Indian studies where height was the best predictor to formulate PEFR. ${ }^{22-28}$ On the other hand we have investigated the multiple regression models with the residual analysis to predict PEFR from physical parameters. We found the equation is as follows:PEFR $=5.930 \times$ Height $(\mathrm{cm})$ $-536.131$

It can be concluded from the present study that as there is no significant difference in mean PEFR values of Indian and Nepalese healthy adults, Indian prediction equations can be used to measure PEFR of Nepalese healthy adults. However, no attempt has been made to evaluate the suitability of the Indian prediction equation for Nepalese healthy adults. So, further study is required for this. However, we tried to make a prediction equation with combined Indian and Nepalese young adults to predict PEFR from height by multiple linear regression equation with residual analysis.

\section{CONCLUSION}

It can be concluded that as there is no significant difference in the mean PEFR values of Indian and Nepalese healthy young adults in the present study, prediction equations made for Indian adults can be used to predict PEFR of Nepalese healthy adults. However, no attempt has been made to evaluate the suitability of the Indian prediction equation for Nepalese healthy young adults. So, further study is required to add more data on there findings. However, we tried to make a prediction equation with combined Indian and Nepalese young adults to predict PEFR by multiple linear regression equation with residual analysis. From this analysis, it has been shown that height is the best predictor for the measurement of the PEFR of the present study.

\section{ACKNOWLEDGEMENT}

The authors are thankful to the Indian and Nepalese MBBS students studying in MCOMS, Pokhara, for their participation in the present study.

\section{REFERENCES}

1. Swaminathan S, Diffey B, Vaz Mario. Evaluating the suitability of prediction equations for lung function in Indian children: A practical approach. Ind Ped 2006;17:680-98.

2. Malik SK, Jindal V, Bansal S. Peak expiratory flow rates in healthy adults. Ind J Chest Dis 1975;17:166-71.

3. Kamath SR, Sarma VS, Raju VRK. Indian norms

for pulmonary function. J Assoce Physicians Ind 1975;25:531-40.

4. Singh HD, Peri S. Peak expiratory flow rate in South Indian adults. Ind J Physiol Pharm 1979;23:315-20.

5. Gupta CK, Mathur N. Statistical model relating peak expiratory flow rate of age, height, weight and sex. J Epidem Comn Hlth 1982;36:64-7. 
6. Chatterjee SP, Saha D, Chatterjee BP. Pulmonary function studies in healthy non smoking men of Calcutta. Annals Hum Biol 1988;15:365-74.

7. Vijayan VK, Rao CV, Venkatesh P, Sankaran K, Reference values and prediction equation for maximal expiratory flow rate in non smoking normal subjects in Madras. Ind J Physiol Pharm 1993;37:291-7.

8. Prasad R, Verma SK, Agrawal GG, Mathur N. Prediction model for peak expiratory flow rate in North Indian population. Ind J Chest Dis and Allied Sci 2006;48:103-6.

9. Johannson ZM, Erasmos LD. Clinical spirometry in normal Bantu. Am Rev Resp Dis 1968;97:585-9.

10. Elbute EA, Femi Pearse D. Peak flow rates in Nigerians. Thorax 1971;26:597-01.

11. Woolcock AJ, Comen MH, Blackburn CRB. Factors effecting normal values for ventilatory function. Am Rev Resp Dis 1972;106:692-09.

12. Gregg I, Nunn J. Peak expiratory flow rates in normal subjects. Br Med J 1973;3:282-4.

13. Prasad BK, Sahay AP, Sing AK. Smoking women and their lung function tests. Kath Univ Med J 2003;2:142-4.

14. Srinivas P, Chia YC, Pai PJ, Kbrahim S. Peak expiratory flow rate in elderly Malaysians. Med J Malaysia 1999;54:11-21.

15. Raju PS, Prasad KV, Ramana YV, Murthy KJ. Pulmonary function tests in Indian Girls- prediction equations in Indian Children. Ind J Pediatr 2004;71:893-7.

16. Hussain S, Mohiuddin M, Shkeel Ur Rehman M, Rafiq A, Ahmed MA. PEFR in cement pipe factory workers. Ind J Physio Pharma 1999;43:405-6.

17. Rasheed BMA, Hussain K, Hussain S. PEFR in relation to phases of pregnancy. Ind J Phyo Pharma

\section{0;44:511-2.}

18. Debray P, Misra J, Ghosh C. Peak expiratory flow rate and cardiorespiratory fitness of Bengali workers exposed to dust and plant source particulate matters. Ind J Com Med 2002;27:171-6

19. Agarwal AN. Measurement of interpretation of peak expiratory flow. Ind J Phyio Pharma 1998;42:567-8.

20. Anscombe FJ. Rejection of outliers. Ttechnometrics 1960;2:23-47.

21. Barnett V, Lewis T. Outliers in statistical data. New York: John Wiley and Sons Inc; 1978.

22. Singh HD, Peri S. Peak expiratory flow rates in South Indian children and adolescence. Ind Peditr 1978;11:473-8.

23. Malik SK, Jindal SK, Sharden PK, Banga N. Peak expiratory flow rate of healthy school boys from Punjab. Ind Pediatr 1981;18:517-21.

24. Aundhakar CD, Kasliwal GJ, Yajurvedi VS, Rawat MS, Ganeriwar SK, Sangam RN. Pulmonary function test in school children. Ind J Physil Pahram 1985;29:14-20.

25. Swaminathan S, Venkatesan P, Mukunathan R. Peak expiratory flow rate in South Indian children. Ind Pediatr 1993;30:207-11.

26. Chougule RV, Shetye VM, Parmar JR. Lung function tests in normal Indian children. Ind Pediatr 1995;32:18591.

27. Pamar VR, Kumar L, Malik SK. Normal values of peak expiratory flow rate in healthy North Indian School children, 6-46 years of age. Ind Peditr 1997;14:591-4.

28. Raju PS, Prasad KVV, Venkata RY, Ahmed KS, Murthy KJR. Study on lung function tests and prediction equations in Indian male children. Ind Pediatr 2003;40:705-11. 